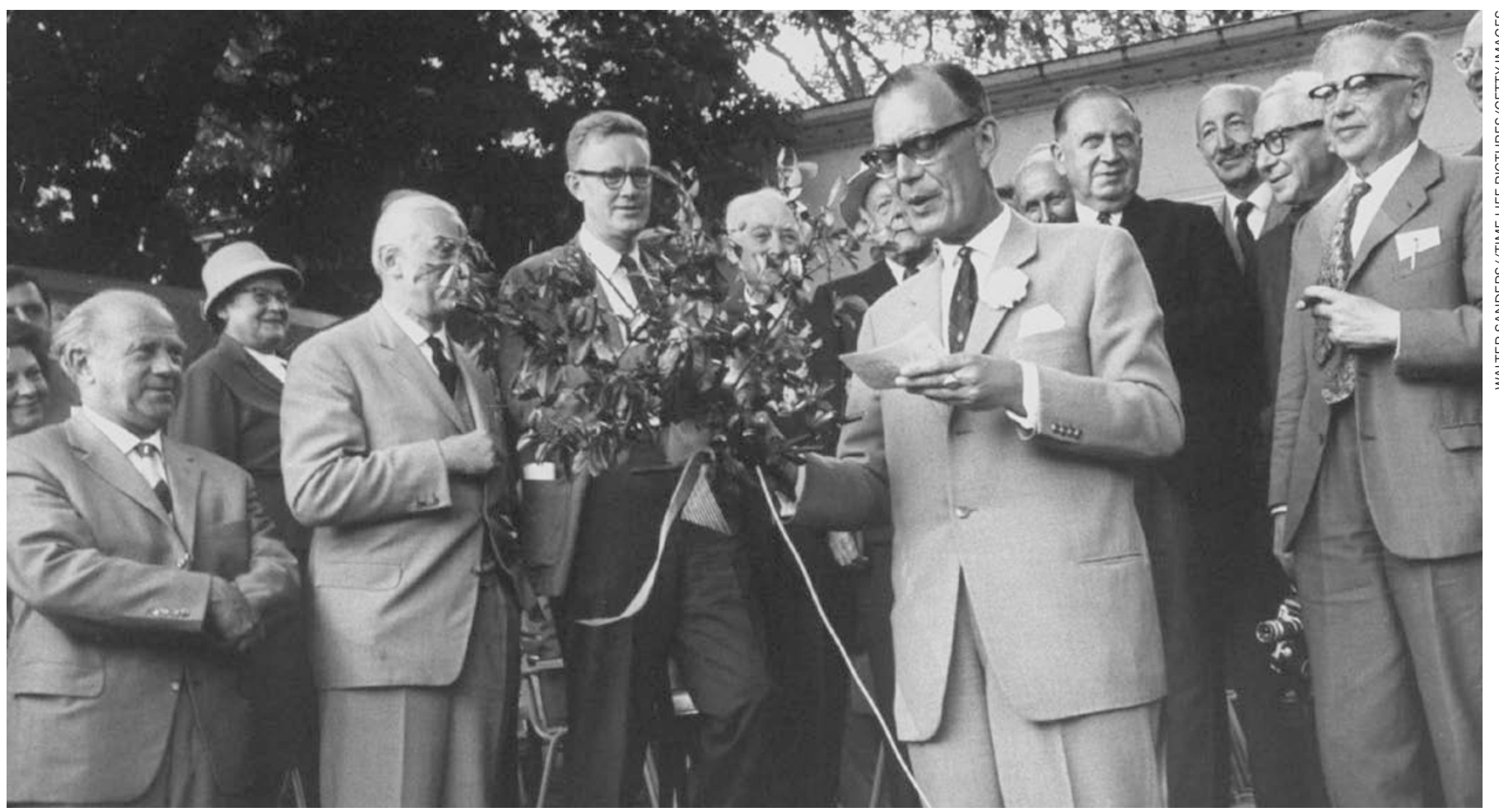

Count Lennart Bernadotte (C) addresses physicists Werner Heisenberg (L), Edward Purcell (3L), Isidor I. Rabi (6R), Emilio Segre (5R), Paul Dirac (2R) and Gustav Hertz (R) at a meeting on Lindau (1962).

\title{
TIMELINE
}

\section{Lindau and the zeitgeist}

\section{The annual Lindau Nobel Laureate Meetings have evolved over the years, reflecting changes in both science and society.}

\section{BY JOHN GALBRAITH SIMMONS}

\section{THE ROAD FROM STOCKHOLM...}

The Nobel Laureate Meetings at Lindau owe their cachet first and foremost to the prestige of the Nobel prize. This prestige, in turn, has much to do with the revolutionary advances in science that were afoot when the prize was first awarded in 1901. Quantum concepts were about to dethrone classical physics. Chemistry, closely allied with atomic physics, would soon extend deep into biology. Major advances in all scientific disciplines would transfigure medicine.

The Nobel also owes its status to scrupulous selection, with an emphasis on rewarding breakthrough discoveries, from the 1901 physics prize for the discovery of X-rays up to the 2009 physiology or medicine award for learning how hromosomes are protected by telomeres and the enzyme telomerase. Now, some 540 awards later, it is clear that the Nobel prizes have also become a touchstone for the public's awareness of the importance of science.

Not all Nobelists are happy recipients. Physicist Richard Feynman, for example, called the prize "a pain in the neck" and molecular biologist Max Delbrück considered rejecting it for being a pointless distraction. But most accept the invasive downside of celebrity as a price worth paying.

The upsides to receiving a Nobel prize are many and diverse. At one end of the spectrum, some recipients are happy to simply take advantage of the enhanced opportunities to continue or broaden their laboratory work. At the other end, some scientists use the Nobel prize as a pulpit to discuss important causes. Most lie in-between.

Which leads to Lindau, where these characteristics of dedication and curiosity, not to mention more ideological viewpoints, are evident each year; putting scientific advances in context in our ever changing world, and helping them to confer, as Alfred Nobel once said, "the greatest benefit on mankind."

\section{...TO LINDAU...}

Occupied and fragmented, post-war Germany was suffering from the scientific brain drain that began with the Third Reich. In 1950, to help jump start the intellectual recovery, local physicians Franz Karl Hein and Gustav Parade decided to organize a meeting in Lindau, a tiny picturesque island-city on Lake Constance, nestled in the southern state of Bavaria. They had two aims: to inform doctors of the latest medical developments, and to promote Germany's reintegration into the wider scientific community.

Hein and Parade believed that the key to achieving these goals was to reach out to Nobel laureates. To this end they enlisted the help of Lennart Bernadotte, who owned the nearby garden island of Mainau. As an aristocrat related to the Swedish royal family, Bernadotte had access to the Nobel committees and was able to gain their unofficial support.

At the first meeting in June 1951, seven laureates lectured 400 physicians and researchers on current scientific concerns. William Murphy, from the United States, discussed pernicious anaemia. Otto Warburg described his theory of photosynthesis. Gerhard Domagk, who had developed the first sulfa drug, an early antimicrobial, but who had been forbidden by the Nazis to collect his award in 1939, talked about treatments for tuberculosis. 
The meeting was widely covered by the German press, and soon turned into an annual event. Young scientists, initially students from the nearby University of Freiburg, started to attend, and gradually the meeting evolved to focus on the interaction between the laureates and the younger scientists.

Lindau attracted quite a following. Many Nobel laureates attended even when not giving formal lectures. Physicists Paul Dirac, Otto Hahn and Werner Heisenberg were regular fixtures for decades. Willis Lamb, the American physicist who discovered the electron Lamb shift and shared the physics prize in 1955 , first attended in 1959 and was planning to attend his 20 th meeting a few weeks before his death in 2008 .

Although Lindau lectures were scientific, during those first few decades the meetings tended to reverberate at the interface of science and society. Early discussions on the development of CERN - the powerful cooperative European particle-physics project took place in Lindau during the 1950s. The creeping shadow of the East-West divide and the cold war could be seen in 1953 when, in the wake of a bloody uprising in East Berlin, East-German scientists were not permitted to attend - a state of affairs that would endure for decades.

Indeed, the nuclear arms race had special importance because many Nobelists had contributed to the advances in nuclear physics - if not to the development of atomic weapons directly. At the Lindau meeting in 1955, the year after the detonation of the hydrogen bomb on Bikini Atoll, American geneticist Hermann Muller gave a lecture discussing the dangers of radiation. Meanwhile, several laureates, including Otto Hahn and quantum physicist Max Born, gathered outside the lecture hall to create an outright pacifist statement. Count Bernadotte read it aloud on the island of Mainau at the traditional close of the meetings, and the 12 laureates present (plus another 40 later on) signed it. Although the Russell-Einstein Manifesto, published a few days earlier, became the foundation document for the anti-nuclear Pugwash movement, the Mainau Declaration underscored the intense concern at the highest echelons of science.

Lindau has been the launch pad for other significant issues over the years. For example, in 1968, Franz König, then Archbishop of Vienna, issued a statement authorized by the Pope that the Catholic Church would consider revising its 1616 censure of Galileo Galilei (although it did not arrive until1992).

Environmentalism and sustainability made early appearances in Lindau, in part because the West German economic miracle came with the price of pollution. Count Bernadotte was a prominent proponent of conservation. His 1961 Green Charter of Mainau contributed to the development of the government-supported conservationist movement in Germany.
The 1990s and the end of the cold war, although not explicitly acknowledged at Lindau, signalled a general move towards closer and more relaxed international relations. But the meeting remained essentially regional, with most foreign students attending simply because they were studying at German universities. "It was a very difficult task to open Lindau to the world," said Ludwig Feinendegen, a physician and researcher in nuclear medicine who joined the Lindau Council in 1979 and later served as its vice president. The interactive aims and informal nature of the meeting worked against funding opportunities, he explained.

There were some successes. By 1998, the Nobel Foundation in Stockholm had begun to appreciate its informal relationship with the Lindau meeting, and that same year the US

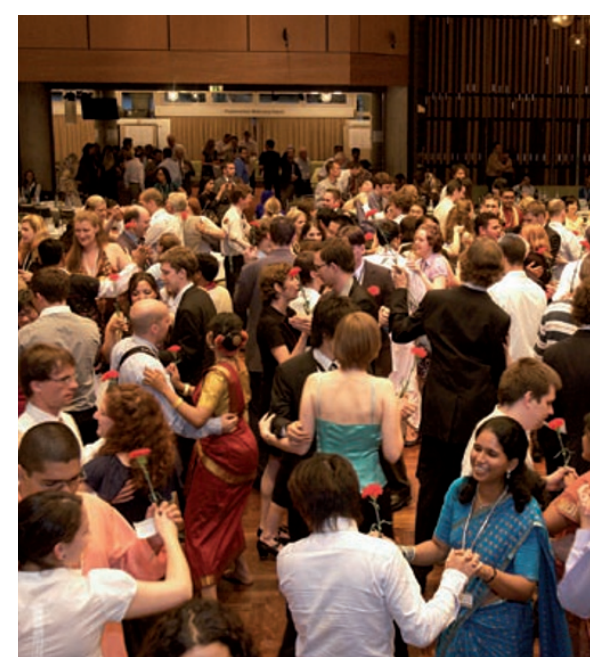

The Polonaise is the traditional dance.

Department of Energy sponsored attendance for a group of young American researchers. Nevertheless, at the turn of the millennium, the meeting was chronically underfunded and somewhat lacking focus. "It became different, less serious over the years," said Anders Bárány, a physicist and former deputy director of the Nobel Museum in Stockholm who is involved in preserving and referencing the meeting's records.

Bárány, whose grandfather Robert won a Nobel prize in 1914, attended his first meeting in 2000. He recalls dancing the traditional Polonaise, partnered with a young greenhaired woman. He asked: "Are you interested in physics?" She was not. Was she going to become a chemist? "No." What about medicine? No again. What then was she doing at Lindau? "I heard it is a nice party."

\section{... TO THE WIDE WORLD OVER}

And so it was, 50 years on from its first gathering, the Lindau meetings needed a makeover. Retaining the central concept of an informal annual meeting, organizers and laureates established a foundation to recast it for the 21st

century. They were not short of expertise.

"We received advice from the laureates themselves on how to chart a new course," recalls Wolfgang Schürer who, as chairman of the board of the new Foundation Lindau Nobelprizewinners Meetings, helped oversee the entire process. "Out of about a dozen very concrete, very specific recommendations from the laureate community, we embarked upon a rediscovery and redesign."

Globalization facilitated this revision, accelerated by the internet. Arno Penzias, who shared the 1978 prize in physics while working for Bell Laboratories, was inspirational in starting the live video stream of lectures and, ultimately, the blogging and extensive social networking that characterized the meeting in 2010. At the same time, the official language was changed from German to English.

Aaron Klug, the 1982 chemistry laureate, is credited with suggesting a partnership strategy, whereby the Lindau Council establishes a network of academic and government institutions to help identify and nominate young researchers, including advanced students, doctoral candidates and postdocs. The council signs a Memorandum of Understanding (MOU) with each institution and a review panel then selects from the nominees.

"We wanted to establish credentials and assure our partners around the world," explains Schürer, "that we want to sustain this effort for decades to come." Ten years later, the Lindau Council has signed more than 200 MOUs worldwide resulting, in 2010, in a record attendance of 61 laureates and 650 young researchers from 72 countries.

Updated and recast, Lindau meetings still follow a scientific agenda that has an ancillary social context. No fewer than five Nobelists at the 2010 meeting addressed the challenges to the environment. The meeting ended with a panel on energy and sustainability. There were also discussions on the prospects for CERN and a debate about the future of medicine.

But the real focus of the meetings at Lindau are the young researchers. Edmond Fischer, who shared the 1992 Nobel Prize in Medicine or Physiology and has regularly attended since 1993, thinks it should be called a "meeting of the students", not prizewinners. "They are the principal component of the meeting. We are coming just for that, to introduce students, to make connections, speak among them, trust one another and speak the same language, the language of science."

Science is not the only beneficiary of the Lindau meetings. The Nobel laureates gain much from keeping in touch with younger scientific minds. "If you look at them when they come and when they go," asserts Bárány, "the meeting is like the fountain of youth."

John Galbraith Simmons is a freelance writer in New York.
ONATURE.COM see Spirit of Lindau go.nature.com/c4Mmzd 